\title{
Educação Ambiental na Modalidade EAD: Um Estudo Bibliométrico
}

\author{
Environmental Education at a Distance: A Bibliometric Study
}

\author{
Macsuel Miranda de Oliveira ${ }^{\text {* }}$ \\ Denise Celeste Godoy \\ de Andrade Rodrigues ${ }^{2}$ \\ ${ }_{12}$ Centro Universitário de Volta \\ Redonda (UniFOA). \\ Av. Paulo Erlei Alves Abrantes, 1325. \\ Volta Redonda, RJ - Brasil. \\ ${ }^{1}$ Faculdade Sul Fluminense (FASF). \\ Rua Alberto Cunha Rodrigues, 39 - \\ Volta Redonda - RJ - Brasil \\ macsuelmiranda@gmail.com \\ 2 Universidade do Estado do Rio de \\ Janeiro (UERJ). Rodovia Presidente \\ Dutra, km 298. Resende, RJ - Brasil.
}

\section{Resumo}

O propósito do presente estudo foi descrever a produção científica sobre Educação Ambiental na modalidade a distância (EaD). Para tanto, foi realizada uma busca no Portal de Periódicos Capes com três argumentos de busca, com base nos quais foram encontrados doze artigos relacionados com Educação Ambiental na modalidade EaD. A pesquisa pode ser classificada, quanto ao seu objetivo, como descritiva. O procedimento técnico adotado foi a pesquisa bibliométrica, a partir da qual foi possível verificar que os estudos relacionados ao tema, em sua maioria, apresentam relatos de ações e práticas relacionados a Educação Ambiental em cursos de extensão. Também foram observados levantamentos, pesquisas documentais, bibliográficas, estudos de caso e observação participante. As instituições que mais se destacaram com pesquisas sobre o tema foram a Universidade Federal de Santa Maria, Universidade Federal do Ceará e Universidade Federal do Rio Grande.

Palavras-chave: Educação a Distância. Educação Ambiental. Bibliometria. 


\section{Environmental Education at a Distance: A Bibliometric Study}

\section{Abstract}

This paper is based on a research study on Environmental Education offered by distance education model (DE). To do so, a search was carried out in the Capes Journal Portal using three search arguments, and 12 articles related to Environmental Education offered at a distance were found. The research can be classified, as its purpose, as descriptive. The technical process used was a bibliometric study, from which it was possible to verify that most studies related to the theme present reports of actions and practices related to Environmental Education in extension courses. Surveys, documents, bibliographic research, case studies, and participant observations were also observed. The institutions that stood out most with research on the subject were the Federal University of Santa Maria, the Federal University of Ceará and the Federal University of Rio Grande.

Keywords: Distance Education. Environmental Education. Bibliometric Study.

\section{Introdução}

De acordo com a Lei n 9.795, de 27 de abril de 1999, a Educação Ambiental pode ser compreendida como um conjunto de processos capazes de fazer com que sejam construídos, individual e coletivamente, "valores sociais, conhecimentos, habilidades, atitudes e competências voltadas para a conservação do meio ambiente, bem de uso comum do povo, essencial à sadia qualidade de vida e sua sustentabilidade" (BRASIL, 1999, p. 1).

A importância da Educação Ambiental se revela, entre outros fatores, pela crescente deterioração das condições de vida, que resultam em uma crise ambiental, demandando ações que possam alterar a forma de pensar e agir quanto às questões ambientais (JACOBI, 2003).

Assim, nas comunidades acadêmica, científica, governamental e social, programas de Educação Ambiental são orientados tendo por base estratégias que permitam que os cidadãos atuem na questão socioambiental (PHILIPI Jr.; PELICIONI, 2002), repensando seus valores, comportamentos, sentimentos e atitudes de modo continuado (MELLO; TRAJBER, 2007). Esses programas podem ser realizados tanto na modalidade de ensino presencial como a distância.

De acordo com o Relatório Analítico de Aprendizagem a Distância no Brasil (2017), há um número elevado de cursos na modalidade a distância no país. Os cursos totalmente a distância chegam a 4.570. Há ainda 3.041 cursos semipresenciais, 16.557 cursos livres não corporativos e 5.574 cursos livres corporativos.

Conforme o mesmo relatório, existem 1.320.025 alunos matriculados em cursos totalmente a distância regulamentados no Brasil, 1.119.031 alunos matriculados em cursos semipresenciais regulamentados, 3.839.958 alunos matriculados em cursos livres e 1.458 .813 alunos matriculados em cursos corporativos.

Bastos, Nunes e Freitas (2014) apresentam um panorama de crescimento da Educação a Distância (EaD) no Brasil paralelo ao aumento das discussões relativas a sustentabilidade. A despeito disso, os autores verificaram que poucos são os estudos sobre a utilização de princípios da sustentabilidade em cursos na modalidade a distância. Destaca-se que a sustentabilidade se refere a um "fim" para o qual a Educação Ambiental é um dos meios (BASTOS; NUNES; FREITAS, 2014). 
Conforme exposto por Silva e Menezes (2001, p. 19), “pesquisar significa, de forma bem simples, procurar respostas para indagações propostas". As pesquisas contribuem para o avanço de determinada área do conhecimento, ao possibilitar respostas aos problemas observados.

Considerando a importância da Educação Ambiental no contexto atual e as contribuições da Educação a Distância, busca-se neste estudo analisar o perfil da produção científica sobre Educação Ambiental a distância com base em pesquisa bibliométrica.

Diante do contexto ora apresentado, o objetivo do presente estudo é definido como: descrever a produção científica sobre Educação Ambiental na modalidade a distância (EaD). Pretende-se responder à seguinte questão-problema: qual o perfil da pesquisa científica sobre a Educação Ambiental a distância?

Esta pesquisa é recorte de uma dissertação de mestrado profissional da área de Ensino de Ciências. Espera-se que a identificação do perfil da pesquisa sobre o tema possibilite conhecer os principais autores, direcionamentos metodológicos, instituições e periódicos com foco no tema, além de lacunas, contribuindo para interessados em pesquisar sobre o assunto.

\subsection{A Educação Ambiental e a Modalidade Educação a Distância}

Educação Ambiental (EA) é o nome dado às práticas educacionais que se referem à questão ambiental (BRASIL, 2004). Trata-se de uma das ferramentas que podem ser utilizadas para sensibilizar e capacitar a população em geral em relação aos problemas ambientais (MARCATTO, 2002).

À EA cabe a construção de novos valores e novas relações da sociedade e dos seres humanos com a natureza, com o intuito de formar atitudes a partir de uma nova ótica: a da melhoria da qualidade de vida para os diversos seres (PHILIPPI Jr.; PELICIONI, 2002). É, portanto, importante instrumento para pôr fim à ignorância ambiental e proporcionar soluções para a superação de problemas existentes entre a preservação do meio ambiente e o desenvolvimento de um país (IBRAHIN, 2014). Constitui uma das estratégias por meio das quais se pode alcançar uma sociedade sustentável (BASTOS et al., 2014).

As instituições de ensino são responsáveis pela promoção da Educação Ambiental integrada aos seus programas educacionais (BRASIL, 1999). De acordo com Ibrahin (2014), a EA não deve ser implantada como disciplina específica em currículos de ensino; isso só poderá ocorrer em cursos de pós-graduação, extensão e em áreas relacionadas à EA.

A Educação a Distância (EaD) é uma modalidade educacional na qual alunos e professores estão física ou temporalmente separados, tornando necessária a utilização de meios e tecnologias de informação e de comunicação (MEC, 2019). É uma modalidade regulada por legislação específica que pode ser implantada na educação de nível básico e superior (MEC, 2019).

Lemgruber (2018) apresenta três gerações de Educação a Distância: na primeira, as ações educacionais ocorrem por correspondência, com a utilização de guias impressos com exercícios, enviados pelo correio. A segunda geração, a partir da década de 1970, também utilizava principalmente o meio impresso, mas também empregava televisores, fitas de áudio e vídeo e telefone. Por fim, a geração atual é classificada pelo autor como a terceira geração, que utiliza fortemente todo o potencial fornecido pela internet.

Essa modalidade educacional conta geralmente com um professor - que elabora materiais instrucionais e planeja estratégias de ensino - e com um tutor - responsável por sanar dúvidas dos alunos (ALMEIDA, 2003). Nesse sentido, é importante que o tutor compreenda a concepção do curso e receba preparo para atuar na função, para que não haja o risco de que seja realizado um atendimento inadequado ao aluno (ALMEIDA, 2003). 
O campo de pesquisa da Educação a Distância evolui na medida do crescimento da própria área de estudo: Mill e Oliveira (2014) observaram que o número de teses sobre o tema aumentou nos últimos anos, acompanhando e expansão da EaD no Brasil. Os autores analisaram teses defendidas entre 2002 e 2012 e verificaram uma maior concentração de teses sobre a Educação a Distância a partir de 2008.

Educação Ambiental e Educação a Distância são dois campos que passam, cada vez mais, a se entrelaçar (LOPES; NEVES, 2014), fornecendo elementos inovadores nos sistemas educacionais: enquanto a Educação Ambiental traz a importância da inserção da dimensão ecológica no cotidiano, tornando o ambientalismo muito mais que um modismo, a Educação a Distância transforma os métodos convencionais de ensino (LOPES; NEVES, 2014).

Bastos et al. (2014) apresentam a Educação a Distância e a Educação Ambiental como duas iniciativas educacionais em crescimento no Brasil, podendo ser justificadas, respectivamente, pela criação da Universidade Aberta do Brasil (UAB) e pelas crescentes pesquisas com o tema Educação Ambiental.

\section{Metodologia}

A presente pesquisa pode ser classificada, quanto ao seu objetivo, como descritiva, uma vez que o propósito é descrever o perfil da pesquisa sobre Educação Ambiental na modalidade a distância (SILVA; MENEZES, 2001). Quanto ao procedimento técnico adotado, esta é uma pesquisa bibliométrica, por realizar a quantificação dos produtos da atividade científica (SANTOS; KOBASHI, 2010).

As buscas ocorreram no mês de março de 2019 no Portal de Periódicos Capes, com três argumentos de busca: "Educação Ambiental" AND “EaD”; “Educação Ambiental” AND “Educação a Distância”; “Educação Ambiental" AND "a distância". Buscou-se por registros do tipo artigo sem recorte temporal, o que significa que todos os artigos disponíveis, desde que contivessem as palavras pesquisadas, seriam verificados, independentemente do ano de publicação.

Após a leitura do resumo dos trabalhos, para confirmar se os artigos eram de fato aderentes ao tema pesquisado (Educação Ambiental na modalidade a distância), os registros foram agrupados. Desse modo, foi possível observar a existência de registros em duplicidade: um mesmo artigo presente em mais de um dos argumentos de busca utilizados. Após a exclusão dos registros em duplicidade, chegou-se ao número total de artigos selecionados para a análise bibliométrica, que é apresentada na próxima seção.

\section{Resultados e Discussão}

O total de registros encontrados na busca e o total de registros selecionados para análise, excluídos aqueles em duplicidade, são apresentados na Tabela 1. 
Tabela 1 - Total de registros encontrados e de artigos selecionados para análise

\begin{tabular}{l|c|c}
\hline \multicolumn{1}{c|}{ Argumento de busca } & $\begin{array}{c}\text { Total de registros } \\
\text { com o uso do argu- } \\
\text { mento }\end{array}$ & $\begin{array}{c}\text { Total de registros } \\
\text { selecionados após } \\
\text { leitura do resumo }\end{array}$ \\
\hline “Educação Ambiental” AND “EaD” & 39 & 7 \\
\hline “Educação Ambiental” AND “Educação a Distância” & 30 & 5 \\
\hline “Educação Ambiental” AND “a Distância” & 52 & 5 \\
\hline Total: & 121 & 18 \\
\hline $\begin{array}{l}\text { Total de artigos após exclusão de registros em dupli- } \\
\text { cidade (presentes em mais de um dos } \\
\text { argumentos de busca utilizados) }\end{array}$ & 11 & \\
\hline
\end{tabular}

Fonte: Elaborado pelos autores, baseado em dados da pesquisa.

No Gráfico 1 são apresentadas as publicações por ano. Observa-se que a primeira publicação encontrada sobre o tema na base consultada data de 2009, o que está alinhado com os achados de Mill e Oliveira (2014), que observaram em sua pesquisa maior concentração de publicações sobre a Educação a Distância a partir de 2008. Os anos de 2012 e 2014 foram aqueles com maior número de publicações sobre o tema, com três artigos publicados em cada ano.

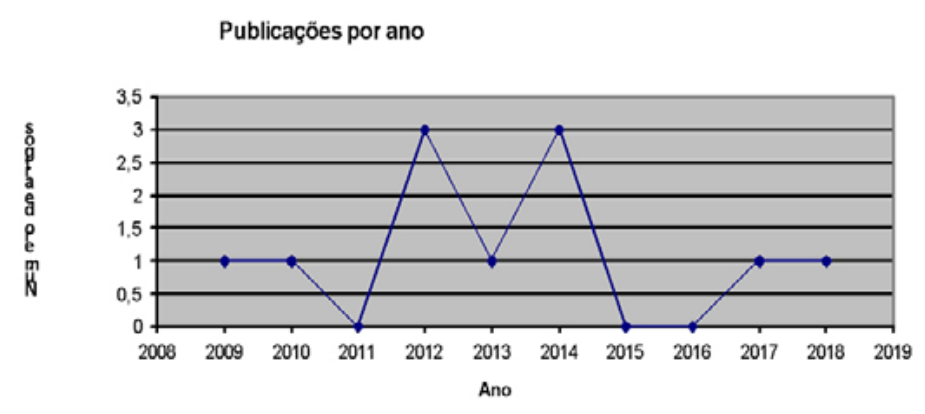

Gráfico 1: Total de publicações por ano

Em relação ao canal de divulgação dos estudos sobre Educação Ambiental na modalidade a distância, destaca-se que a maior parte dos artigos encontrados na plataforma de Periódicos Capes com os argumentos de busca utilizados foi publicada em revistas (10), sendo apenas um em anais de evento. $\mathrm{Na}$ Tabela 2 é apresentada uma lista com as revistas e os eventos, que pode contribuir para os interessados em estudar e/ou publicar pesquisas sobre o tema. 
Tabela 2: Canais de divulgação de estudos sobre Educação Ambiental na modalidade de EaD

\begin{tabular}{|c|c|c|}
\hline Local de publicação & Tipo & Total \\
\hline Augmdomus & \multirow{10}{*}{ Revista } & \multirow{10}{*}{10} \\
\hline Canadian Journal of Latin American and Caribbean Studies & & \\
\hline Monografias Ambientais & & \\
\hline Rev. Elet. em Gestão, Educação e Tecnologia Ambiental & & \\
\hline Revista Eletrônica de Educação & & \\
\hline Extensio: Revista Eletrônica de Extensão & & \\
\hline Revista Intersaberes & & \\
\hline Revista Metropolitana de Sustentabilidade & & \\
\hline Revista Uniara & & \\
\hline Sustinere: Revista de Saúde e Educação & & \\
\hline VIII Congreso Internacional sobre Investigación en la Didáctica de las Ciencias & Congresso & 1 \\
\hline
\end{tabular}

Fonte: Elaborado pelos autores, com base em dados da pesquisa.

Quanto às instituições a que são vinculados os autores dos estudos encontrados, observa-se na Tabela 3 que a Universidade Federal de Santa Maria, a Universidade Federal do Ceará e a Universidade Federal do Rio Grande se destacam, cada uma com dois artigos vinculados. Cabe ressaltar que, em função da possibilidade de um estudo ter mais de um autor, um mesmo estudo pode também ter mais de uma instituição afiliada.

A Universidade Federal de Santa Maria conta com um programa de pós-graduação (especialização e mestrado) em Educação Ambiental que lançou, em 2010, a revista Monografias Ambientais, fato que pode justificar as publicações sobre o tema. A Universidade Federal do Ceará possui um programa de pós-graduação em Desenvolvimento e Meio Ambiente, que originou a Revista Eletrônica do Prodema, cujos focos são a ciência e a prática relacionadas ao desenvolvimento sustentável. Por fim, a Universidade Federal de Rio Grande possui um programa de pós-graduação em Educação Ambiental (mestrado e doutorado), o que pode justificar a iniciativa de pesquisas e publicações sobre o tema. 
Tabela 3: Instituições às quais os artigos se vinculam

\begin{tabular}{l|c}
\hline \multicolumn{1}{|c|}{ Instituições } & $\begin{array}{c}\text { No de } \\
\text { artigos }\end{array}$ \\
\hline Centro Universitário de Araraquara & 1 \\
\hline Centro Universitário Franciscano & 1 \\
\hline Escola de Formação Permanente do Magistério e Gestão Educacional & 1 \\
\hline Faculdade do Vale do Jaguaribe & 1 \\
\hline Faculdade São Luís de Jaboticabal & 1 \\
\hline PUC Paraná & 1 \\
\hline Universidade Federal de Santa Catarina & 1 \\
\hline Universidade Federal de Santa Maria & 2 \\
\hline Universidade Estadual Paulista & 1 \\
\hline Universidade do Estado da Bahia & 1 \\
\hline Universidade Federal do Ceará & 2 \\
\hline Universidade Federal do Paraná & 1 \\
\hline Universidade Federal do Rio Grande & 2 \\
\hline Universidade Federal Rural do Semiárido & 1 \\
\hline
\end{tabular}

Fonte: Elaborado pelos autores com base em dados da pesquisa.

Os procedimentos técnicos adotados no desenvolvimento dos artigos analisados são apresentados no Gráfico 2; com base neles é possível verificar a predominância de estudos com relatos de cursos e atividades relacionadas à Educação Ambiental. Torna-se importante destacar que alguns artigos utilizaram mais de um procedimento técnico; por esse motivo, a soma das ocorrências de cada um deles é superior ao número total de artigos analisados.

Os relatos de atividades se referem, na maior parte, a cursos de extensão. Já as pesquisas documentais basearam-se em leis e projetos pedagógicos de cursos (PPC). Os dois levantamentos concernem a impressão/opinião de participantes e/ou envolvidos em um curso.

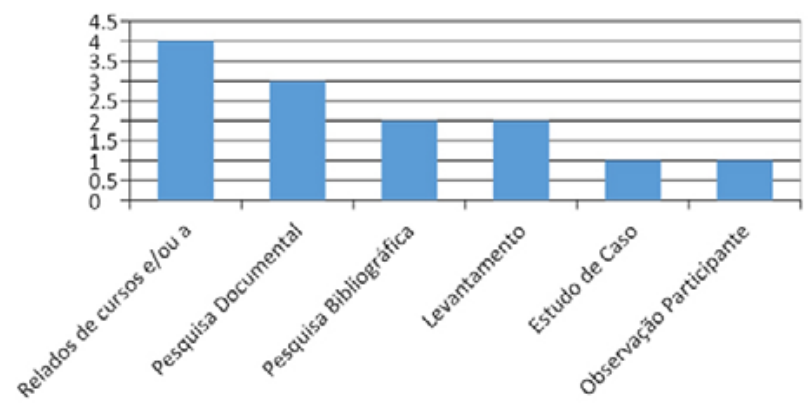

Gráfico 2: Procedimentos técnicos adotados nos estudos analisados

No Quadro 1 são listados os 11 artigos encontrados com os argumentos de busca utilizados na página do Portal de Periódicos Capes, com os periódicos e sua classificação Qualis na área Ensino (quando houver). Espera-se que possa contribuir para interessados em estudar o tema. 
Quadro 1. Título da publicação, periódico e classificação Qualis na área Ensino

\begin{tabular}{|c|c|c|c|}
\hline $\mathrm{N}^{\circ}$ & Título & Periódico & Qualis \\
\hline I & $\begin{array}{l}\text { A Educação Ambiental na modalidade } \\
\text { a distância no Brasil e a investigação de } \\
\text { políticas de avaliação qualitativa }\end{array}$ & Revista Brasileira Multidisciplinar & B4 \\
\hline II & $\begin{array}{l}\text { Educação para a cidadania via rádios } \\
\text { solidárias }\end{array}$ & $\begin{array}{l}\text { Canadian Journal of Latin American and } \\
\text { Caribbean Studies }\end{array}$ & - \\
\hline III & $\begin{array}{l}\text { Uma experiência em EaD: a construção } \\
\text { de uma rede virtual colaborativa no } \\
\text { projeto Escolas Sustentáveis }\end{array}$ & Revista Intersaberes & B3 \\
\hline IV & $\begin{array}{l}\text { Educação para a sustentabilidade } \\
\text { em cursos de graduação a distância: } \\
\text { análise de uma IES pública do } \\
\text { Nordeste do Brasil }\end{array}$ & Revista Eletrônica de Educação & $\mathrm{A} 2$ \\
\hline V & $\begin{array}{l}\text { Desenvolvimento sustentável: } \\
\text { percepção dos alunos do curso de } \\
\text { graduação em Ciências Contábeis das } \\
\text { instituições federais de ensino superior } \\
\text { do Estado do Rio Grande do Sul }\end{array}$ & Revista Metropolitana de Sustentabilidade & - \\
\hline VI & $\begin{array}{l}\text { Estratégias extensionistas do curso de } \\
\text { especialização em Educação Ambiental } \\
\text { da UFSM }\end{array}$ & $\begin{array}{l}\text { Revista Eletrônica em Gestão, Educação e } \\
\text { Tecnologia Ambiental }\end{array}$ & B2 \\
\hline VII & $\begin{array}{l}\text { Educação Ambiental a distância e } \\
\text { o desenvolvimento da consciência } \\
\text { ambiental crítica: um estudo de caso }\end{array}$ & Revista Monografias Ambientais & B1 \\
\hline VIII & $\begin{array}{l}\text { Educação Ambiental a distância } \\
\text { na formação de professores: relato } \\
\text { de uma experiência }\end{array}$ & Augmdomus & - \\
\hline IX & $\begin{array}{l}\text { Um mundo à beira-mar, curso de } \\
\text { capacitação e alternativas didáticas, } \\
\text { uma parceria com a escola do mar }\end{array}$ & Extensio: Revista Eletrônica de Extensão & B5 \\
\hline $\mathrm{X}$ & $\begin{array}{l}\text { Avaliação da efetividade do ensino em } \\
\text { cursos de Educação a Distância }\end{array}$ & Sustinere: Revista de Saúde e Educação & B1 \\
\hline $\mathrm{XI}$ & $\begin{array}{l}\text { Educação Ambiental a distância: } \\
\text { narrativas construtivas de educadores }\end{array}$ & $\begin{array}{l}\text { Repositório institucional da Universidade } \\
\text { Federal do Rio Grande do Norte }\end{array}$ & - \\
\hline
\end{tabular}

Fonte: Elaborado pelos autores, com base em dados da pesquisa.

O artigo I discute a relação entre Educação a Distância e Educação Ambiental, além de "refletir sobre a necessidade de mecanismos de avaliação qualitativa por setores dos órgãos federais competentes" (LOPES, 2014). Para alcançar o objetivo, os autores realizaram pesquisa bibliográfica e documental a partir da qual se verificou que tanto a Educação Ambiental quanto a Educação a Distância buscam seu espaço como política pública, prática pedagógica e meio de disseminação do conhecimento.

O objetivo do artigo II foi analisar a viabilidade da utilização de rádios comunitárias para a educação para a cidadania a distância (VENTURA, 2007). Trata-se de uma pesquisa bibliográfica e documental a partir da qual se destacou que a mídia radiofônica é inclusiva, sendo viável, principalmente, para a educação não formal, como no caso da educação para a cidadania. O artigo destaca ainda a necessidade de melhor emprego dessa mídia para aproveitar suas potencialidades e vencer seus desafios. O artigo está alinhado com o que Lemgruber (2018) apresenta como segunda geração da EaD. Entretanto, a maior parte dos estudos encontrados se relaciona com a terceira geração apresentada pelo autor, por fazer uso da internet. 
No artigo III, Paula et al. (2013) apresentaram resultados da utilização de uma rede virtual e colaborativa de escolas no projeto Escolas Sustentáveis, cujo propósito é divulgar e compartilhar práticas ambientais sustentáveis. O referido projeto objetiva fortalecer as práticas de Educação Ambiental em escolas municipais de Curitiba; por meio da pesquisa, ficou evidenciada sua contribuição para a melhoria da qualidade do ensino.

O objetivo do artigo IV é discutir a Educação para a Sustentabilidade (ES) nas instituições de ensino superior (IES), mais especificamente nos cursos de graduação a distância em uma instituição pública no Nordeste do País (BASTOS; NUNES, 2014). Para alcançar o objetivo, os autores realizaram uma pesquisa documental com base em projetos pedagógicos de cursos (PPC). Os resultados demonstraram que nos PPCs analisados ainda se faz necessária maior atenção quanto às dimensões da sustentabilidade. Apesar disso, os valores de responsabilidade social global estão presentes.

O estudo de Rodrigues et al. (2017), o artigo V, teve por objetivo verificar a percepção de alunos do curso de graduação em Ciências Contábeis de instituições federais de ensino superior do Rio Grande do Sul sobre desenvolvimento sustentável. O procedimento técnico adotado foi o levantamento. Os dados da pesquisa, coletados por meio de um survey, demonstraram que a percepção dos alunos quanto ao tema é, de forma geral, mediana. O estudo revela ainda que a percepção dos alunos concluintes é mais elevada do que as dos iniciantes.

Rosa e Palma (2012), no artigo VI, apresentaram ações extensionistas relacionadas a gestão informacional e divulgação científica do curso de especialização em Educação Ambiental da Universidade Federal de Santa Maria. Os autores descrevem as ações: Congresso Internacional de Educação Ambiental e revista eletrônica Monografias Ambientais.

No artigo VII, Santos (2012) aborda o desenvolvimento de senso crítico em um curso de extensão em Educação Ambiental na modalidade EaD. Nele também são avaliados os fatores que influenciam a apropriação do conhecimento no curso. Quanto à metodologia, pode ser considerado um estudo de caso. Os resultados demonstram que há uma taxa de evasão de $51 \%$ no curso, baixo comprometimento, observado por meio de atrasos na entrega das atividades. Já o desempenho crítico satisfatório dos cursistas foi maior que o insatisfatório. A autora destaca que o uso de fóruns e chats costuma ser mais interessante do que atividades de elaboração de textos opinativos e projetos, em função possivelmente da facilidade de execução.

No estudo do artigo VIII, foi analisado o projeto piloto do curso Consumo Sustentável/Consumo Responsável: Desenvolvimento, Cidadania e Meio Ambiente, na modalidade a distância. Para tanto, Shimizu (2012) realizou observação participante. Concluiu que o curso fornece contribuições aos participantes; entretanto, deve ser reformulado para que seus objetivos educacionais sejam alcançados mais efetivamente nas próximas turmas. Observou-se, ainda, que o curso contribui para reflexões sobre o meio ambiente e sobre as práticas pedagógicas adotadas pelos docentes participantes.

Fonseca et al. (2010) relatam no artigo IX o desenvolvimento e os resultados de um curso em ensino a distância disponibilizado na plataforma Moodle UFSC, elaborado em cinco módulos: “Origem dos Oceanos, Oceanografia como Ciência, O Ambiente Marinho, O Ecossistema Marinho, A llha de Santa Catarina - Ambiente e Ecossistema". Trata-se de uma atividade de extensão.

O estudo apresentado no artigo X, de Oliveira (2018), associa o conceito de efetividade do ensino ao contexto da Educação a Distância para comparar o desempenho de três cursos de formação docente em uma instituição de ensino superior observado a partir de cinco fatores relacionados à qualidade do ensino segundo a percepção discente. Os cursos de extensão foram: Educação Ambiental (EA), Educação em Direitos Humanos (EDH) e Educação de Jovens e Adultos (EJA). Os resultados obtidos apontam para elevado grau de satisfação dos estudantes com sua aprendizagem. 
O trabalho mostrado no artigo XI, de Cousin e Galiazzi (2009), busca analisar a constituição dos educadores ambientais participantes do curso de pós-graduação em Educação Ambiental lato sensu na modalidade a distância. Os autores apresentam atividades propostas no curso, não sendo objetivo do estudo realizar pesquisa aplicada.

Verifica-se que não há, entre os registros encontrados na base consultada a partir dos argumentos de busca utilizados, estudos que relatem a estruturação e a avaliação de cursos de Educação Ambiental na modalidade a distância. A maioria dos relatos apresentados se refere a ações e práticas. Um projeto piloto de curso foi analisado sem que sua concepção fosse descrita. Foi apresentado o desenvolvimento de apenas um curso, entretanto mais voltado para a vida marinha do que para a Educação Ambiental em si.

De forma geral, os estudos estão mais focados em relatar práticas e ações ou avaliar o desempenho ou contribuição. Não foram observados estudos com foco em ações do professor, do tutor e de recursos instrucionais, como material didático e materiais complementares.

\section{Conclusão}

Com base na pesquisa realizada, foi possível responder à questão-problema: qual o perfil da pesquisa científica sobre a Educação Ambiental a distância? Observou-se que os estudos relacionados ao tema são, em sua maioria, relatos de ações e práticas relacionados a Educação Ambiental em cursos de extensão. Também foram observadas pesquisas documentais (baseadas em projetos pedagógicos de cursos), pesquisas bibliográficas, levantamentos, estudo de caso e observação participante.

Não foi possível verificar autores que se destacam em número de artigos publicados sobre o tema. Entre as instituições a que são afiliados os autores dos artigos, destacam-se a Universidade Federal de Santa Maria, a Universidade Federal do Ceará e a Universidade Federal do Rio Grande, instituições que possuem programas de pós-graduação em Educação Ambiental. A maior parte dos artigos se refere à terceira geração da Educação a Distância, uma vez que utilizam a internet. É notório que a evolução da Educação a Distância cria oportunidades para que também as práticas relacionadas à Educação Ambiental sejam realizadas nessa modalidade.

O estudo busca contribuir com interessados em pesquisar sobre o tema, ao apresentar instituições e revistas cujo tema é de interesse e opções metodológicas ainda não abordadas.

Como limitação do estudo, destaca-se a utilização apenas de uma base de dados. A partir da limitação verificada, sugere-se que futuras pesquisas utilizem outras bases e anais de eventos relacionados ao tema como forma de tentar obter maior número de registros relacionados ao tema.

\section{Referências Bibliográficas}

ABED - Associação Brasileira de Educação a Distância. CENSO EAD.BR: relatório analítico da aprendizagem a distância no Brasil 2016 [livro eletrônico]. Curitiba: InterSaberes, 2017.

ALMEIDA, M. E. B. Educação a distância na internet: abordagens e contribuições dos ambientes digitais de aprendizagem. Educação e pesquisa, v. 29, n. 2, p. 327-340, 2003. Disponível em: http://dx.doi. org/10.1590/S1517-97022003000200010. Acesso em: 15 mar. 2019.

BASTOS, A. T.; NUNES, J. B. C.; FREITAS, A. A. F. Educação para a sustentabilidade em cursos de graduação a distância: análise de uma IES pública do Nordeste do Brasil. Revista Eletrônica de Educação, v. 8, n. 3, p. 147-163, 2014. Disponível em: www.reveduc.ufscar.br/index.php/reveduc/article/download/1000/362. Acesso em: 15 mar. 2019. 
BRASIL. Lei $\mathbf{n}^{\circ} 9.795$ de 27 de abril de 1999. Disponível em: http://www.planalto.gov.br/ccivil_03/LEIS/ 19795.htm. Acesso em: 25 abr. 2019.

BRASIL. MINISTÉRIO DA EDUCAÇÃO. O que é Educação a Distância? Disponível em: http://portal.mec. gov.br/escola-de-gestores-da-educacao-basica/355-perguntas-frequentes-911936531/educacao-adistancia-1651636927/12823-o-que-e-educacao-a-distancia. Acesso em: 24 abr. 2019.

BRASIL. MINISTÉRIO DO MEIO AMBIENTE. Identidades da Educação Ambiental Brasileira. Brasília: Edições MMA, 2004.

COUSIN, C. S.; GALIAZZI, M. C. Educação Ambiental a distância: narrativas constitutivas de educadores. 2009. VIII CONGRESO INTERNACIONAL SOBRE INVESTIGACIÓN EN LA DIDÁCTICA DE LAS CIENCIAS. Disponível em: https://www.raco.cat/index.php/Ensenanza/article/download/294172/382713. Acesso em: 05 maio 2019.

FONSECA, A. L. et al. Um mundo à beira-mar, curso de capacitação e alternativas didáticas, uma parceria com a escola do mar. Extensio: Revista Eletrônica de Extensão, v. 7, n. 10, p. 1-08, 2010. Disponível em: https://periodicos.ufsc.br/index.php/extensio/article/view/1807-0221.2010v7n10p1/0. Acesso em: 05 abr. 2019.

IBRAHIN, F. I. D. Educação Ambiental. Estudo dos problemas, ações e instrumentos para o desenvolvimento da sociedade. São Paulo: Érica, 2014.

JACOBI, P. R. Educação Ambiental, cidadania e sustentabilidade. Cadernos de pesquisa, n. 118, p. 189205, 2003. Disponível em: www.scielo.br/pdf/cp/n118/16834.pdf. Acesso em: 05 abr. 2019.

LEMGRUBER, M. S. Educação a Distância: para além dos caixas eletrônicos. Disponível em: http://portal.mec.gov.br/arquivos/conferencia/documentos/marcio lemgruber.pdf. Acesso em: 25 jun. 2019.

LOPES, M. M.; NEVES, F. F. A Educação Ambiental na modalidade a distância no Brasil e a investigação de políticas de avaliação qualitativa. Revista Brasileira Multidisciplinar, v. 17, n. 1, p. 77-87, 2014. Disponível em: www.revistarebram.com/index.php/revistauniara/article/view/8. Acesso em: 05 abr. 2019.

MARCATTO, C. Educação Ambiental: conceitos e princípios. Belo Horizonte: Feam, 2002.

MELLO, S. S.; TRAJBER, R. Vamos cuidar do Brasil: conceitos e práticas em educação ambiental na escola. Brasília: MEC/Coordenação Geral de Educação Ambiental; MMA/Departamento de Educação Ambiental; Unesco, 2007.

MILL, D.; OLIVEIRA, M. R. G. A Educação a Distância em pesquisas acadêmicas: uma análise bibliométrica em teses do campo educacional. Educar em Revista, n. 4, p. 15-36, 2014. Disponível em: https://revistas.ufpr.br/educar/article/view/38642. Acesso em: 15 abr. 2019.

OLIVEIRA RIBEIRO, G. et al. Avaliação da efetividade do ensino em cursos de Educação a Distância. Sustinere: Revista de Saúde e Educação, v. 6, n. 2, p. 222-238, 2018. Disponível em: https://www.e-publicacoes.uerj.br/index.php/sustinere/article/view/36745. Acesso em: 15 abr. 2019.

PAULA, A. de et al. Uma experiência em EaD: a construção de uma rede virtual colaborativa no projeto escolas sustentáveis. Intersaberes, v. 8, n. 16, p. 176-189, 2013. Disponível em: https://www.uninter. com/intersaberes/index.php/revista/article/view/476. Acesso em: 15 abr. 2019.

PHILIPPI Jr., A.; PELICIONI, M. C. F. Educação Ambiental - desenvolvimento de cursos e projetos. $2^{a}$ ed. São Paulo: Signus USP, 2002. 
RODRIGUES, T. C. et al. Desenvolvimento sustentável: percepção dos alunos do curso de graduação em Ciências Contábeis das instituições federais de ensino superior do Estado do Rio Grande do Sul. Revista Metropolitana de Sustentabilidade, v. 7, n. 1, p. 68-90, 2017. Disponível em: http://www.revistaseletronicas.fmu.br/index.php/rms/article/view/1218/pdf. Acesso em: 05 maio 2019.

ROSA, M. B.; PALMA, G. B. Estratégias extensionistas do curso de especialização em educação ambiental da UFSM. Revista Eletrônica em Gestão, Educação e Tecnologia Ambiental, v. 6, n. 6, p. 1.1781.183, 2012. Disponível em: https://periodicos.ufsm.br/reget/article/view/4024/3012. Acesso em: 05 maio 2019.

SANTOS, A. A. Educação Ambiental a distância e o desenvolvimento da consciência ambiental crítica: um relato de caso. Revista Monografias Ambientais, v. 9, n. 9, p. 2.038-2.046, 2012. Disponível em: https://periodicos.ufsm.br/remoa/article/download/5944/3905. Acesso em: 05 maio 2019.

SANTOS, R. N. M.; KOBASHI, N. Y. Bibliometria, cientometria, infometria: conceitos e aplicações. Pesquisa Brasileira em Ciência da Informação e Biblioteconomia, v. 5, n. 1, 2010. Disponível em: periodicos. ufpb.br/ojs/index.php/pbcib/article/view/11992. Acesso em: 05 maio 2019.

SHIMIZU, R. C. G. Educação Ambiental a distância na formação de professores: relato de uma experiência. Augmdomus, v. 4, p. 12-24, 2012. Disponível em: https://revistas.unlp.edu.ar/domus/article/download/470/507/. Acesso em: 05 maio 2019.

SILVA, E. L.; MENEZES, E. M. Metodologia da pesquisa e elaboração de dissertação. $3^{a}$ ed. Florianópolis: UFSM, 2001.

VENTURA, G. C. Educação para cidadania via rádios comunitárias. Canadian Journal of Latin American and Caribbean Studies, v. 32, n. 63, p. 167-185, 2007. Disponível em: https://www.jstor.org/stable/41800600?seq=1\#page_scan_tab_contents. Acesso em: 05 maio 2019. 